\title{
Retirement Intentions \\ Of Female Versus Male Physicians
}

Bahman Bahrami, (E-mail: bahman.bahrami@ndsu.nodak.edu), North Dakota State University Sarah Jacobson, Professor Emeritus, North Dakota State University

\begin{abstract}
Since the percentage of active female physicians in the United States is increasing rapidly, their retirement behavior will represent an important organizational and policy consideration in years to come. The present study, is the first to explore possible differences in retirement intentions among female versus male physicians. Findings are based on data obtained from a random national survey of nearly four thousand physicians regarding factors potentially relevant to their retirement. Our empirical analysis identifies several factors that are correlated with male and female physicians retirement intentions. Significant factors affecting male physicians retirement decisions include: expected social security income, pension income, the availability of early retirement incentives, decreasing annual income, current age, the existence of dependents in the family, years of service as a physician, the health status of ones spouse, stress/burnout, personal interests, the availability of part-time jobs, and general working conditions. In the case of female physicians significant variables are: other expected income, perceived adequacy of retirement income, current age, years of service, work stress/burnout, the availability of part-time jobs, and the employment setting. An understanding of these factors is potentially important for healthcare administrators in dealing with the retention and retirement issues of the female and male physicians and may lead to more effective institutional decision making in this regard.
\end{abstract}

\section{Introduction}

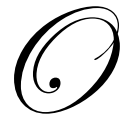

ver the past two decades there has been gradual but dramatic change in the health delivery system. These changes have moved the American health care system from one characterized by physician autonomy and fee for service to one driven by consolidation, managed care, cost containment, bonuses for exceeding set quotas, and control by professional managers. These changes have been accompanied by an apparent increase in the rate of retirement among physicians. An unpublished study by The American Medical Association showed that the average age of doctors at retirement dropped to 67.4 in 1995 from 69.8 in 1980 (Greene, 2000). Merritt Hawkins and Associates, a physician recruiting firm, reported that 38 percent of doctors age 50 or older contacted in a telephone survey between October, 1999 and April 2000 plan to retire within the next one to three years (Hawkins, 2001). It should be noted that the very high proportion of expected retirements at that time may have been somewhat inflated by the relatively high contemporaneous valuation of the aggregate stock market. However, the overall trend toward an aging population of physicians in the United States is clear.

According to The American Medical Association, approximately 34 percent of practicing physicians are age 50 or older (Pasko and Seidman, 2002). As the number of physicians reaching potential retirement age continues to grow, and aging of the baby boom generation approaches, interest in factors affecting physicians' retirement will increase. This issue is particularly cogent since the number of applicants to medical school has declined over the past several years leading some to predict shortages in the availability of health care in many regions of the United States. (Greene, 2000; Thral, 2002). U.S. Medical School applications fell 3.7 percent in 2000, the fourth straight year of decline (The Wall Street Journal, September 5, 2001). Another change in the health delivery system has been the steady increase in the number of female physicians in the fields. Between 1980 and 2000 the percentage of active female physicians increased from 10 percent to 23 percent and this percentage is 
predicted to grow (Salsberg and Forter, 2002). Thus, health care in the United States will be increasingly dependent upon both male and female physicians.

Recognizing the importance of this issue, the present study investigates possible differences in retirement decisions among female versus male physicians. To do so, the study uses a data set obtained by questionnaire from a random national sample of 4,000 physicians, age 50 or older.

\section{Literature Review}

Little research has been conducted to examine attitudes, intentions, and practices regarding retirement among physicians in general. No empirical work has been specifically geared toward an understanding of possible differences in those retirement decisions based on gender. Most of the very limited work that has been published is descriptive and reflects the opinions of professionals in the field. This lack of history of research into the topic may be because retirement was once considered unthinkable for most physicians. "On the one hand, their removal from a profession that has preoccupied them intellectually and emotionally for a lifetime leaves them without important sources of personal gratification and validation. On the other, is a popular perception of retirement as a life with nothing important to do, filled with boredom and an early death" (Virshup and Coombs, 1993). Research indicates that the more a person's self identity is tied to a job, the more likely the person is to retire later (Feldman, 1994). There is evidence however, that retirement behavior and perceptions concerning it among physicians is changing.

In another vein, recent research indicates that the career patterns of female physicians over the span of their working lives differ from those of male colleagues. The differences arise from personal choice and sociocultural imperatives. A majority of female physicians willingly involve themselves in multiple, and often conflicting, responsibilities of work, family, and community activity. The specialty choices of women still cluster in fields that mainly are defined as primary care medicine (More, 1999).

According to Harriet Zuckerman, the career patterns of female physicians are shaped by external social forces and the ways in which individuals have responded to those forces. Female physicians have historically been assumed to be "womanly" as well as "scientific." In addition, the duality of their own experience -- the intersection of professional and feminine cultures, has fostered a situation in which "throughout their history, women physicians have attempted to integrate professionalism with civic and personal life, to sustain an older model of civic professionalism" (Zuckerman, In More 1999).

In 1989, twice as many female as male physicians were employees of larger entities as opposed to being self-employed, even in group practice settings. By 1995, female physicians were still more likely to be employees than their male counterparts, although the percentage of both genders who were employees had increased (More, 1999). Differences in terms of roles as well as employment relationships may differentially affect both the timing and pattern of retirement decisions for a majority of female physicians.

Early physician retirement is a recent trend reported by hospital executives, physician recruiters, and researchers. Frustration with managed care, a perception that the medical field is becoming a trade concerned with bottom-line economics rather than quality care, the high cost of malpractice insurance, and wise financial planning by physicians that allows them latitude in the timing of retirement have all been cited as reasons for the early retirement trend (Thrall, 2001; Greene, 2000; Terry, 1995; Rowe, 1989). The health status of a given physician and/or spouse, the presence of, a favorable pension, and an adequate actual or perceived income have also been cited as reasons for retirement (Rowe, 1989; Virshup and Coombs, 1993). Healthcare professionals also attribute the sudden early retirement of some physicians to burnout and fatigue (Hawkins, 1991). Some writers indicate that increasing demand on physician services in some parts of the country as well as decreasing income are causing some physicians to retire early or leave the region (Goldberg, 1997). Finally, some healthcare experts see physician's dissatisfaction due to long hours and bureaucratic complications with respect to medical practice as the cause of increasing early physician retirement (Hawkins, 1991). 
In writing about retirement behavior among professionals generally, Quinn (1997) notes that the selfemployed often follow very different retirement patterns from those workers who are employed by others. At any given age, the self-employed were more likely than wage and salary workers to retire later--and when they did retire they were less likely to leave the labor force in one move. The potential for many physicians to cut down on their workload, to enter a status of semi-retirement, exists both for those who are self-employed and those who are salaried (Kalogredis, 2000). The availability of "bridge jobs", or phased retirement and volunteer opportunities where they might use their skills in a less demanding way than in full time practice, has been an important factor in enhancing early retirement for many physicians (Kim and Feldman, 2000; Harshman 1998). A number of physicians, particularly those whose identity is closely linked to their professions, may continue to work indefinitely--one study found that some physicians have no plans to retire (Greenfield and Proctor, 1994).

Talaga and Beehr (1995) researched gender differences in predicting retirement decisions generally. They indicate that research on this issue with regard to women has been sparse and results inconsistent. Even definition of the term "retirement" has varied from time to time and study to study. This research has therefore identified many factors acting independently and in concert that may contribute to the motivation for females to remain in the work force rather than retire and/or to return to it post-retirement. These factors are: job characteristics, pension receipt, female longevity, education and training, the number of years worked outside the home, the age at which the woman was last employed, work continuity, full-time versus part-time work, types of occupation, and work satisfaction (Hayes, 1993).

Of special importance for women nearing retirement age today, who were socialized during a previous era, are traditional gender roles that can help to explain some retirement decisions. For example, Talaga and Beehr (1995) found that for men, the odds of retirement decreased based on the number of dependents living in the home. However, for women the results were reversed - the greater the number of dependents living at home the more likely it was that a woman would be retired. Further, their findings support those of Gratton and Haug (1983) who found that the health status of a spouse affects the retirement decision. If the husband's health was poor, women were more likely to be retired. The finding for men was reversed (Talaga \& Beehr, 1995:21). However, this finding must be viewed with some reservation since Szinovacz, DeViney and Davey (2000) found that men with care responsibilities for their wives are more prone to retire. Szinovacz, DeViney and Davey (2000) theorize that the financial costs associated with caregiving for sick relatives may sometimes hinder rather than promote withdrawal from the labor force (S25). The work of Ruhm (1996) supports this hypothesis.

For men, the research has consistently identified two important factors for retirement: the state of ones personal health and retirement income (Gratton and Haug, 1983). Earlier some researchers suggested that retirement provisions such as social security might lead men to leave the workforce at an earlier age than would have been possible prior to this entitlement program (Graebner, 1980. More recent research, however, suggests that the earlier work misspecified the social security variables and underestimated the financial advantages under social security of delaying retirement (Blinder et al., 1980; Clark and Baker, 1981). The effects of the social security program on women's decision to retire is very difficult to measure since, for about one-fifth of all working women collection of retirement benefits as an insured worker provides less income than under "dependent" status as the wife or former wife of an insured husband (Treas, 1981).

Additionally, the decisions of many older married women to retire differ from those of men because many women have discontinuous work histories interrupted by child rearing. This lack of job tenure is correlated with patterns of lower wage rates, reduced occupational mobility, reduced social security benefits, and commitment to work and thus has important consequences for retirement behavior (Felmlee, 1981; Clark et al., 1980). The likelihood of retirement for both males and females is positively influenced by the presence of private pension income from the spouse, but a husband's pension has more influence on a wife's retirement than does her pension on her husband's behavior. In general, the social economic characteristics of the husband have stronger spousal impacts than those of the wife (Clark et al., 1980; Smith and Moen, 1998).

In summary, little research has attempted to discover differences between male and female retirement decisions. In the case of physicians specifically there has been no systematic research analyzing these differences. 
The present study tests an empirical model of retirement intention by utilizing a data set obtained by random national sampling of physicians. This study, builds on previous literature by examining the influence of a set of variables in the personal, financial, work, and organizational domains that may affect differential retirement timing based on gender among physicians and other professionals.

\section{Data}

Data were gathered in 2001 by mail questionnaires from 4,000 randomly selected physicians in all areas of specialization 50 years of age or older, throughout the United States. The questionnaire was designed to be relatively readable and short, in order to facilitate a high response rate. 1,200 surveys were returned; , 791 were usable. The basic characteristics of the sample data were as follows: (1) 11 percent of the respondents were female (reflecting the percentage of female physicians in this age cohort); (2) The average age of respondents was 62.7 years and the average expected age for retirement was 66.5 years; (2) 88 percent of the respondents were married; (3) Respondents reported that their social security income was expected to be $\$ 18,500$ per year on average; (4) The average annual current salary of respondents was reported to be $\$ 132,600$; (5) The average estimated income anticipated from other sources during retirement (spouse's income, pension income, property income, etc.) was $\$ 72,000$; (6) Five percent of the respondents indicated that they do not have any intention to retire unless their health situation forces them to. These latter subjects are potentially informative. Therefore, rather than introduce selection bias by discarding them, we impute the expected retirement age for those individuals who indicate that they have no intention to retire as the life expectancy of the respondent's age cohort.

\section{Empirical Model}

The simple work-leisure choice model of labor supply and labor participation, wherein an individual compares the wage-determined budget constraint with work-leisure preferences and decides on the basis of his/her utility whether or not to continue to be a labor force participant, must be extended when applied to physician retirement decisions based on gender. This study integrates the work-leisure choice model with life-cycle theory, which hypothesizes that people make work, consumption, and other important decisions simultaneously over many time periods. An individual's current decision for the future depends upon the values of relevant variables today and on current expectations of future value. In order to examine this complex decision making process, this study incorporates personal and financial factors, as well as institutional and organizational factors such as working conditions and changes in the structure of healthcare organizations that may affect the decision to retire. Hence, the model employed in this study is:

$E R R A_{i}=f\left(F F_{i}, P F_{i}, I A O F_{i}\right)$

where $E R R A_{i}$ is an individual's expected reported retirement age, $F F_{i}$ are financial factors, $P F_{i}$ are personal factors, and $I A O F_{i}$ are institutional and organizational factors posited to be relevant. The main financial factors, $F F_{i}$ included in the model are current annual salary, expected annual social security income, other income (e.g., spouse's income, pension income, property income), and early retirement incentives. Personal factors, $P F_{i}$, used in this study are age, health status, health status of spouse, caring for family member, preferences for leisure (e.g., gardening, golfing, traveling, spending time with family), years of experience as a physician, and reported burnout. Institutional and organizational factors, $I A O F_{i}$, are working conditions (e.g., changing technology, work rules, pressure to see more patients), changes in the structure of healthcare organizations and the end of mandatory retirement. To estimate the coefficients on the "independent" variables and their impact on the expected retirement age of physicians, the following model is employed:

$E R R A_{i}=a+\sum_{k=1}^{k} B_{k} X_{i, k}+E_{i}$,

where $x_{i, k}$ represents the $k^{\text {th }}$ "independent" variable for the $I^{\text {th }}$ respondent and $B_{k}$ is the associated regression coefficient. 
Because it is very difficult to obtain information on physician retirees' characteristics and on the opportunities available to physicians when they decide to retire, we use the physicians' expected retirement age as the dependent variable. Expected retirement age is not a perfect proxy for actual retirement age, but it is widely used by researchers (see for example, Rees and Smith, 1991; Holden and Hansen, 1989; Anderson, et al., 1986). A vast majority of people do retire at about the planned retirement age and older workers predict their actual retirement ages quite closely (see Anderson, Burkhauser and Quinn, 1986; Burkhauser and Quinn, 1989; Holden and Hansen, 1989). For example, Bernheim (1988) compared expectations with actual retirement and found that in a majority of cases, expected retirement age was an accurate predictor of actual age of retirement. This is probably truer in the present study because the average age of respondents is 62.7 years; many are, therefore, within a few years of actual retirement. Other research indicates that a "linear increase in retirement preparation behaviors takes place over a 15year period before retirement" (Taylor and Shore, 1995). For many people retirement seems to be a well-anticipated and ongoing process, rather than a discrete decision (Quinn, 1997).

\section{Results}

Regarding the regression results for males, (Table 1) our survey variables captured 41 percent of the crosssectional variation in the expected age of retirement, with variables other than current age explaining about 22 percent of the cross-sectional variation in expected age of retirement. The F-test of the restriction that all coefficients are jointly zero was rejected at an extremely low p-value $(\operatorname{Pr}<.0001)$ indicates that the regression is also highly significant (the value of the test statistics is 25.55 , and is distributed $\mathrm{F}(19,711)$.

Table 1. Stepwise Regression for Male Physicians

\begin{tabular}{|l|c|c|c|c|}
\hline Variable & $\begin{array}{c}\text { Parameter } \\
\text { Estimate }\end{array}$ & $\begin{array}{c}\text { Standard } \\
\text { Error }\end{array}$ & F Value* & Pr > F \\
\hline Intercept & 32.98499 & 2.81261 & 137.53 & $<.0001$ \\
AGE & 0.48034 & 0.03707 & 167.92 & $<.0001$ \\
FULDEP & 1.36061 & 0.54393 & 6.26 & 0.0126 \\
NP & -0.80698 & 0.43884 & 3.38 & 0.0664 \\
PENS3 & -0.72097 & 0.41812 & 2.97 & 0.0851 \\
SSI & 0.15539 & 0.03606 & 18.57 & $<.0001$ \\
YRS & 0.08026 & 0.01795 & 20.00 & $<.0001$ \\
HSS & 0.60706 & 0.11100 & 29.91 & $<.0001$ \\
CFM & -0.25443 & 0.14094 & 3.26 & 0.0715 \\
WSB & -0.51450 & 0.13442 & 14.65 & 0.0001 \\
PL & -0.33581 & 0.13869 & 5.86 & 0.0157 \\
ARI & -0.52652 & 0.12872 & 16.73 & $<.0001$ \\
APJ & 0.31478 & 0.12438 & 6.40 & 0.0116 \\
WC & -0.34837 & 0.12875 & 7.32 & 0.0070 \\
ADEA & 0.60013 & 0.14693 & 16.68 & $<.0001$ \\
DI & 0.41518 & 0.13012 & 10.18 & 0.0015 \\
SETTING2 & -1.65774 & 0.60665 & 7.47 & 0.0064 \\
SETTING3 & -1.05968 & 0.51108 & 4.30 & 0.0385 \\
SETTING4 & -1.87249 & 0.87771 & 4.55 & 0.0332 \\
\hline
\end{tabular}

$* F$ value $=(T \text { value })^{2}$ 
The regression results identify several financial, personal, and institutional factors that are correlated with expected retirement age. Among the financial factors are expected social security income (SSI), pension income (PEN3), the availability of early retirement incentives (ARI) and decreasing annual income (DI). As the P values indicate these variables are highly significant. Note that the sign on expected Social Security income is positive, revealing that individuals who expect greater Social Security income tend to retire later. This can be interpreted as follows: other things being equal, higher Social Security income is positively correlated with higher current income, which makes the opportunity costs of retirement greater. This implies that individuals with grater income tend to postpone retirement, so the substitution effect of increased wages (i.e., the increased opportunity cost of leisure tends to postpone retirement) dominates the income effect (i.e., the increased ability to "purchase" leisure tends to hasten retirement). This finding is consistent with those of earlier studies, (see, for example, Holden and Hansen, 1989). Note also that the sign on pension contrasts with the sign on social security income. Earlier studies have shown that "pension income" may tend to reflect underlying wealth. If this is the case, then there is no substitution effect to mitigate the income effect, and so the effect of greater wealth is to hasten retirement (see, for example, Bahrami, 1999). The personal factors affecting the retirement decisions of male are current age (AGE), the existence of dependents (FULDEP), years of service as a physician (YRS), the health status of spouse (HSS), care for family members (CFM), stress and burn out (WSB), and personal interests (PL). Each of the variables has the expected sign and they are significant at $\mathrm{P}=.01$ except variables caring for family member $(\mathrm{P}=.07)$ and personal interests $(\mathrm{P}=.015)$.

Institutional and organizational factors affecting the retirement decision are the availability of part-time jobs (APJ), general working conditions (WC), and the 1986 amendment to the Age Discrimination Act (ADEA). Compared to reference employment setting of academia, multi specialty group $\left(\mathrm{SETTING}_{2}\right)$, single specialty group $\left(\mathrm{SETTING}_{3}\right)$, hospital $\left(\mathrm{SETTING}_{4}\right)$, and public health employment settings (NP) are also significant and cause earlier retirement, Note that the degree of significance of these employment settings variables are not as high as other variables in the model. While general working conditions may proxy for the influence of managed care, our results do not indicate strong evidence that the policies and procedures related to managed care significantly correlated with physicians' expected retirement age, even though physicians indicate that it is an important factor in their retirement decision. One possible reason for these findings is the impact of managed care on lifetime earnings. That is, managed care may make the workplace less desirable, which would tend to induce earlier retirement, but it may also impede the ability of relatively younger physicians to accumulate desired retirement assets through its impact on lifetime earnings. It is still possible, however, or even likely, that over time managed care may substantially impact the supply of physicians by reducing the number of individuals who choose to enter profession due to both pecuniary and non-pecuniary factors.

Regarding female physicians the regression results, (Table 2) indicate that our survey variables captured about 50 percent of the cross-sectional variation in expected age of retirement, with variables other than current age explaining over 37 percent of the cross-sectional variation in expected age of retirement. The regression is also highly significant, as an F-test of the restriction that all coefficients are jointly zero was rejected at a low P-value (the value of the test statistics is 8.63 , and is distributed $\mathrm{F}(9,79)$.

The results of the regression also identify several variables that are correlated with expected age of retirement. Other expected retirement income (OI) (a financial factor) is significant at $\mathrm{P}=.0025$ level indicating that other things being equal an average female physician will retire earlier if she believes that other sources of retirement income (spouse's income, pension, property, etc) are adequate. This variable was not significant in the case of male physicians. This may imply that female physicians are more sensitive than male physicians about the availability of other sources of income such as for example, their spouse's income. This interpretation is also enforced by the PARI (perceived adequacy of retirement income) variable, which is highly significant in the case of the female physicians but not significant for the male physicians. Since many female physicians of this age cohort work in less lucrative fields (e.g., family practice and pediatrics) than do male physicians (e.g., surgical subspecialties) these differences may also reflect life-long income accumulation patterns. 
Table 2. Stepwise Regression for Female

\begin{tabular}{|l|c|c|c|c|}
\hline Variable & $\begin{array}{c}\text { Parameter } \\
\text { Estimate }\end{array}$ & $\begin{array}{c}\text { Standard } \\
\text { Error }\end{array}$ & F Value & Pr > F \\
\hline Intercept & 29.5359 & 9.82071 & 9.05 & 0.0037 \\
AGE & 0.43502 & 0.13866 & 9.84 & 0.0025 \\
OI & -0.06229 & 0.02557 & 5.94 & 0.0174 \\
TRS & 0.17316 & 0.06704 & 6.67 & 0.0119 \\
WSB & 0.86633 & 0.44272 & 3.83 & 0.0544 \\
APJ & 1.31956 & 0.41344 & 10.19 & 0.0021 \\
PARI & -1.14321 & 0.43755 & 6.83 & 0.011 \\
ADEA & 1.7613 & 0.41257 & 18.22 & $<.0001$ \\
SETTING2 & -3.70865 & 2.32966 & 2.53 & 0.4459 \\
\hline
\end{tabular}

The personal factors significantly affecting the retirement decision of the female physicians are current age, years of service, and work stress/burn-out. Two of these factors (current age, and years of service) are consistent with the male physicians and they have the expected sign. The sign of variable for stress/burn-out is different for the two groups. For the male physicians stress/burn-out causes earlier retirement and is highly significant but for the female physicians this factor delays retirement and the degree of significance is not high. This might imply that female physicians are more tolerant of work conditions and more adaptable to the changes in health delivery system than male physicians. Or, it may indicate that female physicians delay retirement based on economic factors despite high levels of perceived stress and/or burn-out. In addition the WC (general working conditions) variable is significant for the male physicians in predicting retirement but not for the female physicians. Again, interpretation of this finding is complex. It may mean that female physicians are more tolerant of deteriorating working conditions or it may mean that they must tolerate them due to financial considerations. Male physicians also are more sensitive about the decrease in income that retirement represents as well as the chance to pursue personal interests such as golfing, traveling, etc. in retirement than are female physicians. For female physicians these factors are not significant.

Among institutional factors affecting both groups are the availability of part-time jobs, the 1986 amendment to the Age Discrimination Act, and the employment setting. Employment settings of single specialty group, public institution, and hospital are not significant for the female physicians but are for male physicians (reference group in analysis of employment settings is working for academia).

\section{Future Research}

Results of this study suggest several possible, and potentially important, directions for future research. First, we know that retirement is a dynamic process, that the decision to retire is often a gradual one made over a period of many years. Therefore, in order to fully understand the nature of this process, longitudinal research following a specific age cohort of physicians of both genders over a period of several years prior to retirement would be required. This amplified view of the retirement decision process would be valuable in understanding physician behavior and might have potential applicability for members of other professions. Second, while quantitative research such as that employed in the present study is valuable in terms of validity and generalizability, it is less useful in terms of understanding the meaning of concepts and decision processes for those being studied. Therefore, qualitative research in the form of structured interviewing or Q-sorting and focused on retirement behavior would be potentially useful. Finally, we know that the experience (both in the past and present) of the current age cohort of physicians who are facing retirement cannot be projected into the future. Medicine is a rapidly changing profession; many of those who are entering the field today will face a very different economic and social reality as they reach retirement age. Therefore, ongoing research on physician retirement will clearly be necessary in order to achieve timely understanding of the phenomenon. 


\section{Conclusion and Discussion}

The use of survey methodology in this project made it possible to investigate the perceived importance of a wide variety of factors on the retirement intentions of female and male physicians surveyed. Because this study appears to be the first systematic examination of the differences in factors affecting retirement intentions between female and male physicians, the survey included as many factors as possible drawn from prior research in the retirement domain. While a close connection between retirement intentions and actual behavior has been established in the past (Bernheim, 1988) the cross-sectional design of this study does not allow for inferences of causality. Therefore, further research, following older female and male physicians through the pre-retirement and post-retirement periods is needed in order to gain full understanding of the retirement process and the complex interplay of different factors affecting retirement patterns. Feldman (1994) suggests that such research might incorporate panel studies of potential retirees following their decision-making processes from the initial decision to retire through the actual event.

Further, as indicated earlier, the present research design creates some problems of endogeneity and common method variance. While reliance on self-report in terms of gender, family status, age, and other demographic variables is likely to be accurate, respondents may have distorted responses in other cases. Health and financial status, for example, have been found to be particularly vulnerable to this kind of distortion in previous retirement research (Feldman, 2000; Anderson and Burkhauser, 1985). While this problem could be corrected through linking self-reports with verifiable archival data (Kim and Feldman, 2000), obtaining such data across a broad sample of physicians such as that surveyed in this study would be impractical. However, because of possible distortion, some caution should be exercised in interpreting our results.

Results of the study identified several factors that affect the retirement decisions of male and female physicians. Some of these factors are not directly controllable by administrators and human resource planners. For example, the presence of other sources of income and/or preferences for leisure are individual factors that are largely unaffected by institutional action or policy. However, some of the factors identified as being important in this research are potentially modifiable through institutional rules, policies, and practices. For example, the presence of part-time work options was found to be a highly significant factor in the timing of retirement for both male and female physicians. Providing opportunities for phased retirement could be an appropriate policy in attempting to retain those physicians who hold value for the organization. Such arrangements might be especially important for female physicians because perceived adequacy of retirement income is particularly significant in their case and parttime work would allow them to supplement that income.

A more complete understanding of additional factors affecting the timing of retirement behavior both within and across gender drawn from further longitudinal research, would provide and clarify further insights for policy makers in healthcare organizations. Since, effective healthcare in the United States will be increasingly dependent on the presence of female physicians as well as male, attention to differential factors influencing their retirement decisions are critical.

While our analysis shows that female physicians are more concerned about the availability of other income (e.g., spouse's income, pension income, etc.), and perceived adequacy of retirement income than are male physicians, male physicians are more concerned about the presence of dependents in the household and decreasing income due to changes in the health care system. Male physicians are also more affected by work related stress and burnout in terms of the timing of their retirement. Employment settings and working conditions, therefore, may have higher priority for male than female physicians. By reducing bureaucratic red tape, facilitating open communication, and establishing internal advisory committees to discover sources of work related stress and other negative organizational issues, healthcare administrators can modify work environments to positively affect individual behavior. Intentional manipulation of factors identified as affecting the retirement of both male and female physicians will help hospitals and other healthcare organizations to ensure seamless care for patients and avoid losses of revenue. 


\section{References}

1. Anderson, R.H., Burkhauser R., and Quinn, J.F. (1986). Do Retirement Dreams Come True? The Effects of Unanticipated Events on Retirement Plans. Industrial and Labor Relations Review, 39 (4), 518-526.

2. Anderson, R.H., and Burkhauser, R. (1985). The retirement-health nexus: A new measure for and old puzzle. Journal of Human Resources, 19(2), 285-306.

3. Bahrami, B. (1999). Determinants of Faculty Early Retirement Decisions, The Journal of Economics, Vol. XXV, No. 2, 73-87.

4. Bernheim, B.D., (1988). "Social Security Benefits: An Empirical Study of Expectations and Realizations, in Ricardo"-Campbell R. and E. LaZear (Eds.). Issues in Contemporary Retirement. Stanford, CA: Hoover Institution, cited in Holden and Hansen (Eds.). The end of mandatory retirement: effects on higher education, new directions for higher education, San Francisco: Jossey-Bass, Inc (p 66).

5. Blinder, A.S. et al. (1980). Reconsidering The Work Disincentive Effects of Social Security, National Tax Journal, 33, 431-443.

6. Burkhauser, R., and Quinn, J.F. (1989). "An Economy-Wide View of Changing Mandatory Retirement Rules", in Holden and Hansen (Eds.), The end of mandatory retirement: effects on higher education, new directions for higher education, San Francisco: Jossey-Bass, Inc. (63-64).

7. $\quad$ Clark, R.L. and Baker D.T. (1981). Reversing The Trend toward Early Retirement. Washington, D.C., American Enterprise Institute for Public Research.

8. Clark, R.T., Johnson, T. and McDermed, A.A. (1980). "Allocation of Time and Resources by Married Couples approaching retirement", Social Security Bulletin, 43, 3-17.

9. Feldman, D.C. (1994). "The Decision to Retire Early: A Review and Conceptualization", The Academy of Management Review, 2 (19), 285-306.

10. Felmlee, D.H. (1981). "The consequences of employment discontinuity for women's occupational attainment, presented at the meeting of The American Sociological Association", August, Toronto, cited in Gratton, B. and Haug, M.R., (1988). Decision and Adaptation, Research on Aging, 5(1), 59-76.

11. Goldberg, C. (1997). "MD Incomes are suffering”, Long Island Business News, 51(2), 1-3.

12. Graebner, W. (1980). A History of Retirement. New Haven, CT, Yale University Press.

13. Gratton, B. and Haug, M.R. (1983). "Decision and Adaptation: Research on Female Retirement", Research on Aging, 5(1), 59-76.

14. Greene, J. (2000). "Physicians enticed into early retirement". American Medical News, July 24, www.amaassn.org/sci-pubs/amnews/pick_00/pr120724.htm>.

15. Greenfield, L. and Proctor, M. (1994). "Attitudes toward retirement: A survey of the American Surgical Association". Annals of Surgery, 220(3), 382-390.

16. Harsham, P. (1998). "Senior doctors, senior care: An idea that works". Medical Economics, 75, 235-239.

17. Hawkins, J. (1991). "Planning for Early MD Retirement", Trustee, 1(44), 14-18.

18. Hawkins, J. (2001). "Administrators should Help Restore the Image of Physicians", Healthcare Strategic Management, 10(9), 14-17.

19. Hayes, C.L. (1993). Women in Mid-Life: Planning for Tomorrow, Binghamton, NY, Harrington Park Press.

20. Holden, K.C. and Hansen, W.L. (1989). "The End of Mandatory Retirement: Effects on Higher Education", New Directions for Higher Education, San Francisco: Jossey-Bass, Inc.

21. Kalogredis, V.J. (2002). "It's Not Too Early To Prepare for Semi-Retirement", Family Practice Management, 2(9), 57-58.

22. Kim, S. and Feldman, D.C. (2000). "Working in retirement: The antecedents of bridge employment and its consequences for quality of life in retirement". Academy of Management Journal, 43 (6), 1195-1210.

23. More, E.S. (1999), Restoring The Balance: Women Physicians and The Profession of Medicine, 1850-1995, Cambridge, Massachusetts, Harvard University Press.

24. Pasko, T. and Seidman, B. (2002). Physician Characteristics and Distribution in the US, 2002-2003 Edition, American Medical Association, AMA Press U.S.A.

25. Quinn, J.F. (1997). "The Role of Bridge Jobs in the Retirement Pattern of Older Americans in the 1990s". In D.L. Salisbury (Ed.) Retirement Prospects in a Defined Contribution World. Washington, D.C.: Employee Benefit Research Institute, 25-39. 
26. Rees, A., and Smith, S.P. (1991). Faculty Retirement in the Arts and Sciences. New Jersey: Princeton University Press.

27. Rowe, M.L. (1989). "Health, income, and activities of retired physicians". New York State Journal of Medicine, 89, 450-453.

28. Ruhm. C.J. (1996). "Gender Differences in Employment Behavior During Late Middle Age", Journal of Gerontology: Social Sciences 51B (1), 11-17.

29. Salsberg, E.S. and Forte, G.J. (2002). "Trends in the physician workforce", 1980-2000, Health Affairs, 21(5), 165-173.

30. Smith, D.B. and Moen, P. (1998). "Spousal Influence on Retirement: His, Her, and their perceptions", Journal of Marriage and The Family, 60 (August), 734-744.

31. Szinovaez, M.E., DeViney, S., and Davey, A. (2001). "Influences of Family Obligations and Relationships on Retirement: Variations by Gender, Race, and Marital Status". Journal of Gerontology: Social sciences, 56B (1), 20-27.

32. Talaga, J.A. and Beehr, T.A. (1995). "Are There Gender Differences in Predicting Retirement Decisions?" Journal of Applied Psychology, 80(1), 16-28.

33. Taylor, M.A. and Shore, L.M. (1995). "Predictors of Planned Retirement Age: An Application of Beehr's Model". Psychology and Aging, 10(1), 76-83.

34. Treas, J. (1981). "Women's Employment and its Implications for the status of the elderly of the future", cited in Gratton, B., and Haug M.R. (1983). Decision and Adaptation, Research on Aging, 5(1), 59-76.

35. Thrall, T.H. (2002). "Doctor Dearth". Hospitals and Health Networks, Chicago, 75(3), 50-54.

36. Virshup, B. and Coombs, R.H. (1993). "Physicians' adjustment to retirement". The Western Journal of Medicine, 158(2), 142-144.

37. Zuckerman, H. (1989). Accumulation of Advantages and Disadvantages: The Theory and its Intellectual Biography, In More, E.S. (1999), "Restoring the Balance", Cambridge, Massachusetts, Harvard University Press, (P8). 